\title{
Daya Hasil 15 Galur Cabai IPB dan Ketahanannya terhadap Penyakit Antraknosa yang Disebabkan oleh Colletotrichum acutatum
}

\section{Yield and Resistance to Anthracnose Disease Caused by Colletotrichum acutatum of IPB Chili Pepper Lines}

\author{
Lia Marliyanti ${ }^{1}$, Muhamad Syukur ${ }^{1 *}$, dan Widodo ${ }^{2}$ \\ ${ }^{1}$ Departemen Agronomi dan Hortikultura, Fakultas Pertanian, Fakultas Pertanian, Institut Pertanian Bogor \\ (Bogor Agricultural University), Jl. Meranti Kampus IPB Darmaga 16680, Indonesia \\ ${ }^{2}$ Departemen Proteksi Tanaman, Fakultas Pertanian Institut Pertanian Bogor (Bogor Agricultural University), Jl. \\ Meranti Kampus IPB Darmaga 16680, Indonesia
}

\begin{abstract}
This research intended to evaluate the yield of 15 IPB chili pepper lines from Plant Genetics and Breeding Division, Department of Agronomy and Horticulture, IPB, and was compared then with 5 commercial varieties. This research also intended to evaluate its resistance to anthracnose. This research was done from January until July 2011 at Bogor. The main character that evaluated was yield component and resistant to character. IPB019015, IPB110005, IPB120005, IPB009019, IPB002046, and IPB001004 had yield ability better than commercial varieties. IPB019015 had resistance to anthracnose disease better than commercial varieties.
\end{abstract}

Keywords: anthracnose, chili, yield component

\section{ABSTRAK}

Penelitian ini bertujuan untuk mengevaluasi daya hasil 15 galur cabai koleksi Bagian Genetika dan Pemuliaan Tanaman, Departemen Agronomi dan Hortikultura, IPB, dan kemudian membandingkannya dengan 5 varietas komersial. Penelitian ini juga bertujuan untuk mengevaluasi galur cabai yang tahan terhadap antraknosa. Penelitian ini dilaksanakan dari bulan Januari sampai Juli 2011 di Bogor. Karakter utama yang dievaluasi adalah komponen hasil dan ketahanan terhadap penyakit antraknosa. IPB019015, IPB110005, IPB120005, IPB009019, IPB002046, dan IPB001004 memiliki daya hasil yang lebih baik dibandingkan varietas komersial. IPB019015 memiliki ketahanan terhadap penyakit antraknosa yang lebih baik dibandingkan varietas komersial.

Kata kunci: antraknosa, cabai, komponen hasil

\section{PENDAHULUAN}

Cabai (Capsicum annuum L.) merupakan komoditas sayuran semusim yang banyak dibudidayakan di Indonesia. Produksi cabai termasuk tinggi dibandingkan dengan komoditas sayuran lainnya di Indonesia. Dari tahun ke tahun, produksi cabai di Indonesia mengalami fluktuasi. Produksi cabai berfluktuasi dari tahun 2005-2010 berturut-turut yaitu 1058023 ton, 1185057 ton, 1128792 ton, 1 153060 ton, 1378727 ton, dan 1328864 ton. Luas panen cabai pada tahun 2009 sebesar 233904 ha, dan

\footnotetext{
* Penulis untuk korespondensi. e-mail: muhsyukur@ipb.ac.id
}

untuk produktivitasnya 5.89 ton ha-1. Tahun 2010, luas panen cabai meningkat menjadi sebesar 237105 ha, namun produktivitasnya menurun menjadi 5.60 ton ha-1 (BPS, 2011). Produktivitas cabai tersebut masih rendah dibandingkan potensinya. Potensi produktivitas cabai dapat mencapai 20 ton ha-1 (Syukur et al., 2010).

Benih bermutu dari varietas unggul merupakan salah satu faktor yang mempengaruhi keberhasilan produksi, sehingga perakitan varietas unggul diperlukan untuk meningkatkan produktivitas cabai (Syukur et al., 2010). Selain hal tersebut, tanaman cabai banyak mendapat gangguan dari hama dan penyakit sehingga menurunkan produktivitas cabai 
(Semangun, 2000). Antraknosa merupakan penyakit utama yang menyerang cabai (Suryaningsih et al., 1996). Antraknosa dapat menyebabkan kehilangan hasil sebesar $10-80 \%$ di musim hujan dan 2-35\% di musim kemarau (Widodo, 2007). Varietas cabai komersial yang memiliki ketahanan terhadap antraknosa, umumnya berdaya hasil rendah dan bentuk buahnya tidak disukai pasar (Syukur et al., 2009). Oleh karena itu, diperlukan varietas unggul yang memiliki produktivitas dan ketahanan terhadap hama dan penyakit yang tinggi.

Pengujian terhadap calon varietas merupakan salah satu kegiatan yang harus dilakukan dalam proses pendaftaran varietas untuk peredaran benih hortikultura (Direktorat Perbenihan Hortikultura, 2011). Dari hasil pengujian terhadap calon varietas dapat diketahui produktivitas dan adaptabilitasnya. Calon varietas yang diuji juga diharapkan memiliki ketahanan terhadap penyakit yang lebih baik dibandingkan varietas yang beredar saat ini. Jika hasil pengujian dari calon varietas dinyatakan memiliki keunggulan, maka varietas yang diuji dapat menjadi varietas unggul yang baru.

Tujuan dari penelitian ini adalah mempelajari daya hasil dan ketahanan terhadap penyakit antraknosa 15 galur cabai IPB dan lima varietas pembanding.

\section{BAHAN DAN METODE}

Penelitian ini terbagi menjadi dua Penelitian ini terdiri atas evaluasi daya hasil di Kebun Percobaan Leuwikopo IPB Dramaga, dan evaluasi ketahanan terhadap penyakit antraknosa di Laboratorium Genetika dan Pemuliaan Tanaman, Departemen Agronomi dan Hortikultura Fakultas Pertanian IPB. Penelitian dilakukan pada bulan Januari sampai dengan Juli 2011.

Bahan tanaman yang digunakan dalam penelitian ini adalah 15 galur cabai IPB yaitu IPB110005, IPB120005, IPB001004, IPB002003, IPB002005, IPB002046, IPB015002, IPB002001, IPB009002, IPB009003, IPB009004, IPB009015, IPB009019, IPB015008, IPB019015, dan lima varietas pembanding, yaitu Tombak, Gelora, Tit Super, Trisula, Lembang I. Bahan inokulum yang digunakan yaitu isolat Colletotrichum acutatum PYK 04 dan KDI S02.

Percobaandilakukanmenggunakan Rancangan Kelompok Lengkap Teracak (RKLT), faktor tunggal (15 galur cabai IPB dan lima varietas pembanding) dengan tiga ulangan. Setiap satuan percobaan terdiri dari 20 tanaman.

Bedengan dibuat dengan lebar $1 \mathrm{~m}$, panjang $5 \mathrm{~m}$, tinggi $30 \mathrm{~cm}$, dan jarak antar bedeng $50 \mathrm{~cm}$.
Bedengan tersebut diberi pupuk kandang sebanyak 20 ton/ha pada dua minggu sebelum tanam, dan pupuk urea (400 kg ha-1), KCl (300 kg ha-1), dan SP-36 (300 $\mathrm{kg}$ ha-1) kemudian ditutup dengan mulsa plastik hitam perak pada satu minggu sebelum tanam. Jarak tanam yang digunakan yaitu $50 \mathrm{~cm} \times 50 \mathrm{~cm}$.

Pemindahan bibit ke lapangan dilakukan pada 8 MSS (minggu setelah tanam). Pemeliharaan tanaman cabai yang dilakukan yaitu penyiraman, penyulaman, pewiwilan, penyiangan gulma, pemupukan, pengendalian hama dan penyakit.

Pengamatan dilakukan pada 12 tanaman contoh pada setiap ulangan. Karakter yang diamati meliputi umur berbunga (HST), umur berbuah (HST), bobot per buah $(\mathrm{g})$, panjang buah $(\mathrm{cm})$, diameter buah $(\mathrm{mm})$, tebal daging buah $(\mathrm{mm})$, kadar capsaicin ( $\mathrm{ppm})$, jumlah buah, dan bobot buah per tanaman (g).

Data yang diperoleh diuji menggunakan analisis ragam. Jika hasil pengujian menunjukkan pengaruh yang nyata, maka akan dilakukan uji beda nilai tengah dengan menggunakan Uji Dunnett pada taraf $5 \%$.

Persiapan inokulum dan inkubasi setelah inokulasi mengikuti prosedur Yoon (2003). Isolat cendawan C. acutatum ditumbuhkan pada media potato dextrose agar (PDA). Setelah tujuh hari, media PDA disiram aquades dan konidia diambil dari cawan. Kepadatan inokulum diatur mencapai 5.0 x 105 konidia/ml dengan hemasitometer.

Enam puluh buah cabai yang sudah tua tetapi masih hijau yang terbagi menjadi tiga ulangan untuk masing-masing genotipe diinokulasi dengan inokulum C. acutatum. Buah yang akan diinokulasi dicuci menggunakan akuades. Inokulasi dilakukan dengan cara menyuntikkan $2 \mu 1$ suspensi konidia sebanyak dua suntikan pada daerah yang berbeda (untuk buah yang berukuran $<4 \mathrm{~cm}$ hanya satu suntikan per buah). Untuk mempelajari mekanisme ketahanan fisik dilakukan pula inokulasi dengan cara mencelupkan buah ke dalam suspensi konidia. Buah yang telah diinokulasi kemudian ditempatkan di atas kawat dalam bak plastik. Untuk menjaga kelembaban, pada dasar bak plastik diletakkan tisue basah. Bak kemudian ditutup dengan plastik hitam dan diinkubasi pada suhu 25oC selama lima hari.

Kejadian penyakit diamati pada lima hari setelah inokulasi. Kriteria ketahanan terhadap penyakit antraknosa berdasarkan persentase kejadian penyakit diduga menggunakan metode Yoon (2003) yang dimodifikasi yaitu $0 \leq \mathrm{X}<10 \%$ : sangat tahan, $10<\mathrm{X}<20 \%$ : tahan, $20<\mathrm{X}<40 \%$ : moderat, $40<$ $\mathrm{X}<70 \%$ : rentan, dan $\mathrm{X}>70$ : sangat rentan. Kejadian penyakit dihitung dengan rumus: $\mathrm{KP}=(\mathrm{n} / \mathrm{N}) \times 100 \%$. 
KP adalah kejadian penyakit, $\mathrm{n}$ adalah jumlah buah yang terserang, yaitu jika diameter gejala $>4 \mathrm{~mm}$ dan $\mathrm{N}$ adalah jumlah buah yang diinokulasi.

\section{HASIL DAN PEMBAHASAN}

\section{Karakter Kuantitatif}

Umur berbunga pada galur yang diuji berkisar antara 24 - 31.67 HST. Galur IPB002001 memiliki umur berbunga lebih cepat dibandingkan Tombak, namun tidak berbeda dengan Gelora, Tit super, Trisula dan Lembang I. Galur IPB009003 memiliki umur berbunga lebih lama dibandingkan Gelora, Tit Super, Trisula, dan Lembang I, namun tidak berbeda dengan Tombak. Galur IPB120005 memiliki umur berbunga lebih cepat dibandingkan dengan varietas Tombak dan Lembang I (Tabel 1).

Umur berbuah pada galur yang diuji berkisar antara 69-80 HST. Galur IPB015002 dan IPB009015

Tabel 1. Nilai tengah karakter umur berbunga, umur berbuah, bobot buah, dan panjang buah 15 galur cabai IPB dan 5 varietas pembanding

\begin{tabular}{|c|c|c|c|c|}
\hline Genotipe & $\begin{array}{c}\text { Umur } \\
\text { Berbunga }\end{array}$ & $\begin{array}{l}\text { Umur } \\
\text { Berbuah }\end{array}$ & $\begin{array}{c}\text { Bobot } \\
\text { Buah }\end{array}$ & $\begin{array}{c}\text { Panjang } \\
\text { Buah }\end{array}$ \\
\hline & (HST) & (HST) & (g) & $(\mathrm{cm})$ \\
\hline IPB110005 & 31.33abd & $77.67 \mathrm{~b}$ & $8.83 \mathrm{cde}$ & 14.2 \\
\hline IPB120005 & $26.33 b c$ & $76.67 \mathrm{bc}$ & $9.98 \mathrm{cde}$ & $14.81 \mathrm{ae}$ \\
\hline IPB001004 & $25.00 \mathrm{c}$ & $72.00 \mathrm{ce}$ & $8.03 \mathrm{bcde}$ & $11.07 \mathrm{bcd}$ \\
\hline IPB002003 & $25.67 \mathrm{c}$ & $71.33 \mathrm{ce}$ & $9.12 \mathrm{cde}$ & $12.03 \mathrm{~cd}$ \\
\hline IPB002005 & $25.67 \mathrm{c}$ & $71.00 \mathrm{ce}$ & $10.24 \mathrm{cde}$ & 13.11 \\
\hline IPB002046 & $24.67 \mathrm{c}$ & $73.00 \mathrm{bc}$ & $11.20 \mathrm{ce}$ & 17.89abcde \\
\hline IPB015002 & $25.67 \mathrm{c}$ & $69.00 \mathrm{ce}$ & $7.99 \mathrm{bcde}$ & $12.20 \mathrm{~cd}$ \\
\hline IPB002001 & $24.00 \mathrm{c}$ & $72.00 \mathrm{ce}$ & $11.28 \mathrm{ce}$ & $11.87 \mathrm{~cd}$ \\
\hline IPB009002 & $27.33 b c$ & $75.00 \mathrm{bc}$ & $8.42 \mathrm{bcde}$ & 13.92 \\
\hline IPB009003 & 31.67abde & $79.67 \mathrm{ab}$ & $7.41 \mathrm{bcde}$ & $10.85 \mathrm{bcd}$ \\
\hline IPB009004 & $25.33 \mathrm{c}$ & $70.00 \mathrm{ce}$ & $8.47 \mathrm{bcde}$ & 13.53 \\
\hline IPB009015 & $28.00 \mathrm{ab}$ & $69.00 \mathrm{ce}$ & $9.01 \mathrm{cde}$ & 9.81 abcde \\
\hline IPB009019 & $26.67 \mathrm{bc}$ & $72.00 \mathrm{ce}$ & 13.08ace & 17.07abe \\
\hline IPB015008 & 29.33abd & $75.00 \mathrm{bc}$ & $8.15 \mathrm{bcde}$ & $10.86 \mathrm{bcd}$ \\
\hline IPB019015 & 28.67abd & 80.00abd & $9.44 \mathrm{cde}$ & $12.46 \mathrm{~cd}$ \\
\hline Gelora & 23.67 & 71 & 9.18 & 12.24 \\
\hline Tit Super & 21.67 & 64.33 & 11.3 & 13.16 \\
\hline Tombak & 31.67 & 84.67 & 21.94 & 15.6 \\
\hline Trisula & 24.33 & 72 & 12.57 & 15.12 \\
\hline Lembang 1 & 27.33 & 80.67 & 3.15 & 12.4 \\
\hline
\end{tabular}

Keterangan: Angka yang diikuti oleh huruf a, b, c, d dan e berturut-turut berbeda nyata dengan Gelora, Tit Super, Tombak, Trisula dan Lembang I berdasarkan uji Dunnett taraf 5\% memiliki umur berbuah lebih cepat dibandingkan Tombak dan Lembang I, namun tidak berbeda dengan Gelora, Tit Super dan Trisula. Galur IPB019015 memiliki umur berbuah lebih lama dibandingkan Gelora, Tit Super, dan Trisula, namun tidak berbeda dengan Tombak dan Lembang I. Galur IPB120005 memiliki umur berbuah lebih cepat dibandingkan Tombak dan Lembang I (Tabel 1).

Galur IPB009003 memiliki bobot buah lebih kecil dibandingkan dengan Tit Super, Tombak, Trisula, namun tidak berbeda dengan Gelora. Galur IPB009019 memiliki bobot buah lebih besar dibandingkan dengan Gelora dan Lembang I, namun tidak berbeda dengan Tit Super dan Trisula. Bobot buah pada galur IPB120005 lebih besar dibandingkan Gelora dan Lembang I, namun tidak berbeda dengan Tit Super (Tabel 1).

Galur IPB009015 memiliki panjang buah lebih kecil dibandingkan dengan seluruh varietas pembanding. Galur IPB002046 memiliki panjang buah lebih besar dibandingkan dengan seluruh varietas pembanding. Panjang buah pada galur IPB120005 lebih besar dibandingkan Gelora, Tit Super dan Lembang I, namun tidak berbeda dengan Tombak dan Trisula (Tabel 1).

Galur IPB009003 memiliki diameter buah lebih kecil dibandingkan dengan Tit Super, Tombak, dan Trisula namun tidak berbeda dengan Gelora. Galur IPB019015 memiliki diameter buah lebih besar dibandingkan dengan Gelora dan Lembang I namun tidak berbeda dengan Tit Super dan Trisula. Diameter buah pada galur IPB110005 dan IPB120005 lebih besar dibandingkan dengan varietas Gelora dan Lembang I (Tabel 2).

Galur IPB019015 memiliki tebal daging buah lebih kecil dibandingkan dengan Gelora, Tit Super, Tombak dan Trisula, namun tidak lebih kecil dibandingkan Lembang I. Galur IPB009015 memiliki tebal daging buah lebih besar dibandingkan dengan Lembang I, namun tidak berbeda dengan Gelora, Tit Super, Tombak dan Trisula. Tebal daging buah pada galur IPB120005 lebih besar dibandingkan Tit Super dan Lembang I, namun tidak berbeda dengan Gelora, Tombak, dan Trisula (Tabel 2).

Capsaicin merupakan salah satu karakter biokimia cabai yang berperan dalam menentukan rasa pedas (Greenleaf, 1986). Semakin tinggi kadar capsaicin, maka akan semakin tinggi tingkat kepedasannya. Galur IPB002046 memiliki kadar capsaicin paling rendah dibandingkan dengan Lembang I, namun masih lebih tinggi dibandingkan dengan Gelora, Tit Super, Tombak dan Trisula. Galur IPB019015 memiliki kadar capsaicin lebih tinggi dibandingkan dengan seluruh varietas pembanding. 
Galur IPB110005 dan IPB120005 memiliki kadar capsaicin lebih tinggi dibandingkan dengan seluruh varietas pembanding (Tabel 2).

Galur IPB009019 memiliki jumlah buah lebih sedikit dibandingkan Lembang I, namun tidak berbeda dengan Gelora, Tit Super, Tombak dan Trisula. Galur IPB001004 dan IPB110005 memiliki jumlah buah lebih banyak dibandingkan dengan Gelora, Tit Super, Tombak dan Trisula, namun tidak berbeda dengan Lembang I (Tabel 3).

Galur IPB015002 memiliki bobot buah total per tanaman dan produktivitas lebih kecil dibandingkan Tombak, namun tidak berbeda dengan Gelora, Tit Super, Trisula, dan Lembang I. Galur IPB019015 memiliki bobot buah total per tanaman dan produktivitas lebih besar dibandingkan dengan Lembang I, namun tidak berbeda dengan Gelora, Tit Super, Tombak dan Trisula. Bobot buah total per tanaman dan produktivitas pada galur IPB110005 dan

Tabel 2. Nilai tengah karakter diameter buah, tebal daging buah, dan kadar capsaicin 15 galur cabai IPB dan 5 varietas pembanding

\begin{tabular}{lllc}
\hline Genotipe & $\begin{array}{c}\text { Diameter } \\
\text { Buah }(\mathrm{mm})\end{array}$ & $\begin{array}{c}\text { Tebal } \\
\text { Daging } \\
\text { Buah } \\
(\mathrm{mm})\end{array}$ & $\begin{array}{c}\text { Kadar Capsaicin } \\
(\mathrm{ppm})\end{array}$ \\
\hline IPB110005 & $14.22 \mathrm{abcde}$ & 1.68 & $987.15 \mathrm{abcde}$ \\
IPB120005 & $14.65 \mathrm{abcde}$ & 1.74 & $1241.69 \mathrm{abcde}$ \\
IPB001004 & $13.84 \mathrm{bcde}$ & 1.75 & $911.25 \mathrm{abcd}$ \\
IPB002003 & $14.57 \mathrm{abcde}$ & 1.62 & $859.73 \mathrm{abcd}$ \\
IPB002005 & $14.88 \mathrm{acde}$ & 1.93 & $948.20 \mathrm{abcde}$ \\
IPB002046 & $14.20 \mathrm{abcde}$ & $1.99 \mathrm{e}$ & $617.95 \mathrm{abcde}$ \\
IPB015002 & $12.12 \mathrm{bcde}$ & 1.91 & $1117.92 \mathrm{abcde}$ \\
IPB002001 & $16.65 \mathrm{ace}$ & $2.19 \mathrm{e}$ & $781.81 \mathrm{abcde}$ \\
IPB009002 & $12.72 \mathrm{bcde}$ & 1.57 & $966.64 \mathrm{abcde}$ \\
IPB009003 & $11.71 \mathrm{bcde}$ & 1.86 & $853.60 \mathrm{abcd}$ \\
IPB009004 & $11.93 \mathrm{bcde}$ & 1.73 & $861.46 \mathrm{abcd}$ \\
IPB009015 & $15.97 \mathrm{ace}$ & $2.26 \mathrm{e}$ & $906.35 \mathrm{abcd}$ \\
IPB009019 & $15.97 \mathrm{ace}$ & $2.11 \mathrm{e}$ & $1052.84 \mathrm{abcde}$ \\
IPB015008 & $15.71 \mathrm{ace}$ & 1.62 & $829.77 \mathrm{abcd}$ \\
IPB019015 & $19.05 \mathrm{ace}$ & 1.54 & $1340.99 \mathrm{abcde}$ \\
Gelora & 11.41 & 2.2 & 195.46 \\
Tit Super & 17.29 & 1.73 & 184.35 \\
Tombak & 21.99 & 2.28 & 150.88 \\
Trisula & 17.75 & 1.83 & 238.81 \\
Lembang 1 & 7.12 & 1.13 & 863.97 \\
\hline & & & \\
\hline
\end{tabular}

Keterangan : Angka yang diikuti oleh huruf a, b, c, d dan e berturut-turut berbeda nyata dengan Gelora, Tit Super, Tombak, Trisula dan Lembang I berdasarkan uji Dunnett taraf 5\%
IPB120005 lebih besar dibandingkan dengan Gelora, Tit Super, dan Lembang I, namun tidak berbeda dengan Tombak dan Trisula (Tabel 3).

Menurut hasil penelitian Mastaufan (2011), galur IPB009019 memiliki hasil yang tinggi, dalam hal bobot buah total per tanaman dan produktivitas pada musim tanam sebelumnya. Sama halnya dengan penelitian ini, galur IPB009019 memiliki bobot buah total per tanaman dan produktivitas yang tinggi. Hal tersebut menunjukkan bahwa galur IPB009019 memiliki daya adaptasi yang baik terhadap lingkungan Bogor pada dua musim tanam yang berbeda.

\section{Ketahanan Terhadap Penyakit Antraknosa}

Kejadian penyakit pada galur yang diuji menggunakan isolat PYK04 berkisar antara 75$96.67 \%$. Seluruh galur yang diuji masuk ke dalam kriteria sangat rentan. Kejadian penyakit pada galur yang diuji menggunakan isolat KDIS02 berkisar antara $30-73.33 \%$.

Tabel 3. Nilai tengah karakter produksi pada 15 galur cabai IPB dan 5 varietas pembanding

\begin{tabular}{lccl}
\hline Genotipe & $\begin{array}{c}\text { Jumlah Buah } \\
\text { per Tanaman }\end{array}$ & $\begin{array}{c}\text { Bobot Buah } \\
\text { Total per } \\
\text { Tanaman }(\mathrm{g})\end{array}$ & $\begin{array}{c}\text { Produktivitas } \\
\text { (ton/ha) }\end{array}$ \\
\hline IPB110005 & $121.42 \mathrm{abcd}$ & $767.62 \mathrm{e}$ & $24.56 \mathrm{e}$ \\
IPB120005 & $77.78 \mathrm{e}$ & $742.15 \mathrm{e}$ & $23.75 \mathrm{e}$ \\
IPB001004 & $108.14 \mathrm{abcd}$ & $794.73 \mathrm{e}$ & $25.43 \mathrm{e}$ \\
IPB002003 & $86.89 \mathrm{bce}$ & 672.41 & 21.52 \\
IPB002005 & $80.56 \mathrm{ce}$ & 695.66 & 22.26 \\
IPB002046 & $70.50 \mathrm{e}$ & $813.50 \mathrm{e}$ & $26.03 \mathrm{e}$ \\
IPB015002 & $86.05 \mathrm{bce}$ & $580.54 \mathrm{c}$ & $18.58 \mathrm{c}$ \\
IPB002001 & $68.92 \mathrm{e}$ & $732.36 \mathrm{e}$ & $23.43 \mathrm{e}$ \\
IPB009002 & $92.00 \mathrm{bce}$ & 706.75 & 22.62 \\
IPB009003 & $99.50 \mathrm{abc}$ & 632.10 & 20.22 \\
IPB009004 & $99.25 \mathrm{abc}$ & 629.54 & 20.14 \\
IPB009015 & $103.81 \mathrm{abcd}$ & $739.71 \mathrm{e}$ & $23.67 \mathrm{e}$ \\
IPB009019 & $68.55 \mathrm{e}$ & $854.68 \mathrm{e}$ & $27.35 \mathrm{e}$ \\
IPB015008 & $73.41 \mathrm{e}$ & 630.53 & 20.18 \\
IPB019015 & $106.28 \mathrm{abcd}$ & $912.19 \mathrm{e}$ & $29.19 \mathrm{e}$ \\
Gelora & 64.72 & 634.66 & 20.31 \\
Tit Super & 52.42 & 648.00 & 20.74 \\
Tombak & 47.81 & 937.74 & 30.10 \\
Trisula & 68.33 & 813.37 & 26.30 \\
Lembang 1 & 126.19 & 389.98 & 12.48 \\
\hline
\end{tabular}

Keterangan : Angka yang diikuti oleh huruf a, b, c, d dan e berturut-turut berbeda nyata dengan Gelora, Tit Super, Tombak, Trisula dan Lembang I berdasarkan uji Dunnett taraf 5\% 
Galur IPB002046 dan IPB009015 termasuk dalam kriteria sangat rentan sama seperti varietas Tombak. Galur IPB120005, IPB015002, IPB002001 dan IPB019015 termasuk dalam kriteria moderat. Galur IPB110005, IPB001004, IPB002003, IPB002005, IPB009002, IPB009003, IPB009004, IPB009019 dan IPB015008 termasuk dalam kriteria rentan sama dengan varietas Gelora, Tit Super, Trisula, dan Lembang I (Tabel 4).

Galur IPB120005, IPB015002, IPB002001 dan IPB019015 termasuk dalam kriteria moderat pada saat diuji menggunakan isolat KDIS02, namun galurgalur tersebut termasuk dalam kriteria sangat rentan pada pengujian menggunakan isolat PYK04 (Tabel 4). Hal tersebut menunjukkan bahwa isolat PYK04 lebih virulen jika dibandingkan KDIS02.

Perbedaan genotipe yang diuji memberikan pengaruh yang nyata terhadap diameter nekrosis pada pengujian menggunakan isolat PYK04, namun perbedaan genotipe yang diuji tidak memberikan pengaruh yang nyata terhadap diameter nekrosis pada pengujian menggunakan isolat KDIS02. Nilai KK

Tabel 4. Kriteria ketahanan 15 galur cabai IPB dan 5 varietas pembanding

\begin{tabular}{lcccc}
\hline Genotipe & \multicolumn{4}{c}{ Kejadian Penyakit (\%) } \\
\cline { 2 - 5 } & PYK04 & Kriteria & KDIS02 & Kriteria \\
\hline IPB110005 & 93.33 & SR & 56.67 & $\mathrm{R}$ \\
IPB120005 & 90.00 & SR & 35.00 & $\mathrm{M}$ \\
IPB001004 & 91.67 & SR & 63.33 & $\mathrm{R}$ \\
IPB002003 & 91.67 & SR & 48.33 & $\mathrm{R}$ \\
IPB002005 & 85.00 & SR & 53.33 & $\mathrm{R}$ \\
IPB002046 & 96.67 & SR & 73.33 & $\mathrm{SR}$ \\
IPB015002 & 86.67 & $\mathrm{SR}$ & 30.00 & $\mathrm{M}$ \\
IPB002001 & 96.67 & $\mathrm{SR}$ & 38.33 & $\mathrm{M}$ \\
IPB009002 & 89.67 & $\mathrm{SR}$ & 65.00 & $\mathrm{R}$ \\
IPB009003 & 93.33 & $\mathrm{SR}$ & 53.33 & $\mathrm{R}$ \\
IPB009004 & 93.33 & $\mathrm{SR}$ & 68.33 & $\mathrm{R}$ \\
IPB009015 & 91.67 & $\mathrm{SR}$ & 71.67 & $\mathrm{SR}$ \\
IPB009019 & 75.00 & $\mathrm{SR}$ & 55.00 & $\mathrm{R}$ \\
IPB015008 & 95.00 & $\mathrm{SR}$ & 60.00 & $\mathrm{R}$ \\
IPB019015 & 78.33 & $\mathrm{SR}$ & 33.33 & $\mathrm{M}$ \\
Gelora & 85.00 & $\mathrm{SR}$ & 46.67 & $\mathrm{R}$ \\
Tit Super & 88.33 & $\mathrm{SR}$ & 46.67 & $\mathrm{R}$ \\
Tombak & 98.33 & $\mathrm{SR}$ & 71.67 & $\mathrm{SR}$ \\
Trisula & 81.67 & $\mathrm{SR}$ & 51.67 & $\mathrm{R}$ \\
Lembang I & 96.67 & $\mathrm{SR}$ & 66.67 & $\mathrm{R}$ \\
\hline
\end{tabular}

Keterangan : $\mathrm{SR}=$ sangat rentan, $\mathrm{R}=$ rentan, $\mathrm{M}=$ moderat
Tabel 5. Rekapitulasi sidik ragam diameter

\begin{tabular}{lcc}
\hline Isolat & Kuadrat Tengah & KK $(\%)$ \\
\hline PYK04 & $0.09^{* *}$ & 11.43 \\
KDIS02 & 0.03 tn & 11.74 \\
\hline
\end{tabular}

Keterangan : ** berpengaruh nyata pada taraf $1 \%$, tn tidak berpengaruh nyata

pada kedua isolat tidak jauh berbeda. Isolat PYK 04 memiliki nilai KK $11.43 \%$, sedangkan untuk isolat KDIS02 sebesar 11.74\% (Tabel 5).

Berdasarkan Tabel 6, perlakuan isolat dan genotipe berpengaruh nyata terhadap diameter nekrosis, sedangkan interaksi antara isolat dan genotipe tidak berpengaruh nyata terhadap diameter nekrosis. Hasil tersebut menunjukkan bahwa tidak adanya pengaruh perbedaan isolat yang digunakan terhadap diameter nekrosis pada masing-masing genotipe yang diuji.

Diameter nekrosis merupakan indikator tingkat serangan penyakit antraknosa. Diameter nekrosis yang semakin lebar menunjukkan tingkat serangan yang lebih tinggi karena semakin lebar pula jaringan kulit yang rusak. Pada pengujian menggunakan isolat PYK04, galur IPB120005 memiliki diameter nekrosis yang lebih kecil dibandingkan Tit Super, Tombak, Trisula, dan Lembang I. Galur IPB002003 memiliki diameter nekrosis lebih besar dibandingkan Gelora dan Trisula, namun tidak berbeda dengan Tit Super, dan Tombak. Galur IPB019015 memiliki diameter nekrosis lebih kecil dibandingkan Tit Super, Tombak, dan Trisula (Tabel 7).

Pada pengujian menggunakan isolat KDIS02, galur IPB002005 memiliki diameter nekrosis yang lebih kecil dibandingkan Gelora dan Tombak, namun tidak lebih kecil dibandingkan Tit Super dan Trisula. Galur IPB001004 memiliki diameter nekrosis lebih besar dibandingkan dengan Gelora, Tit Super, Tombak dan Trisula. Galur IPB120005 memiliki diameter

Tabel 6. Rekapitulasi sidik ragam analisis gabungan pada diameter nekrosis

\begin{tabular}{lc}
\hline Sumber & Kuadrat Tengah \\
\hline Ulangan | Isolat & $0.19^{* *}$ \\
Genotipe & $0.08^{* *}$ \\
Interaksi Isolat*Genotipe & $0.04 \mathrm{tn}$ \\
KK $: 11.64 \%$ & \\
\hline
\end{tabular}

Keterangan : $\quad * *$ berpengaruh nyata pada taraf $1 \%$, ${ }^{\mathrm{n}}$ tidak berpengaruh nyata 
Tabel 7. Pengamatan diameter nekrosis 15 galur cabai IPB dan 5 varietas pembanding

\begin{tabular}{llc}
\hline \multirow{2}{*}{ Genotipe } & \multicolumn{2}{c}{ Diameter Nekrosis $(\mathrm{cm})$} \\
\cline { 2 - 3 } & PYK 04 & KDI S02 \\
\hline IPB110005 & $1.81 \mathrm{a}$ & 1.22 \\
IPB120005 & 1.35 & 1.20 \\
IPB001004 & 1.75 & 1.43 \\
IPB002003 & $1.98 \mathrm{ad}$ & 1.31 \\
IPB002005 & 1.53 & 1.16 \\
IPB002046 & 1.73 & 1.26 \\
IPB015002 & 1.51 & 1.28 \\
IPB002001 & $1.81 \mathrm{a}$ & 1.25 \\
IPB009002 & $1.87 \mathrm{a}$ & 1.37 \\
IPB009003 & 1.52 & 1.30 \\
IPB009004 & 1.65 & 1.17 \\
IPB009015 & 1.69 & 1.39 \\
IPB009019 & 1.58 & 1.22 \\
IPB015008 & 1.62 & 1.18 \\
IPB019015 & 1.44 & 1.20 \\
Gelora & 1.31 & 1.28 \\
Tit Super & 1.80 & 1.12 \\
Tombak & 1.73 & 1.42 \\
Trisula & 1.50 & 1.13 \\
Lembang I & 1.61 & 1.35 \\
\hline Ko
\end{tabular}

Keterangan : Angka yang diikuti oleh huruf a, b, c, d dan e berturut-turut berbeda nyata dengan Gelora, Tit Super, Tombak, Trisula dan Lembang I berdasarkan uji Dunnett taraf 5\%

nekrosis yang lebih kecil dibandingkan Gelora, Tombak, dan Lembang I (Tabel 7).

\section{KESIMPULAN}

Galur IPB019015, IPB009019 dan IPB002046 memiliki bobotbuah total per tanaman dan produktivitas lebih tinggi dibandingkan dengan varietas pembanding Gelora, Tit Super, dan Trisula. Galur IPB110005 dan IPB120005 memiliki bobot buah total per tanaman dan produktivitas lebih tinggi dibandingkan dengan varietas pembanding Lembang I, Gelora, dan Tit Super. Galur IPB019015, IPB001004 dan IPB110005 memiliki jumlah buah per tanaman lebih tinggi dibandingkan dengan varietas pembanding Gelora, Tit Super, Tombak, dan Trisula.

Uji ketahanan terhadap antraknosa dengan menggunakan isolat PYK04 menunjukkan bahwa galur
IPB009019 dan IPB019015 memiliki ketahanan yang lebih baik dibandingkan dengan varietas pembanding Gelora, Tit Super, Tombak, dan Trisula. Uji ketahanan dengan menggunakan isolat KDIS02 menunjukkan bahwa galur IPB120005 memiliki ketahanan yang lebih baik dibandingkan dengan seluruh varietas pembanding, sedangkan galur IPB019015 dan IPB015002 memiliki ketahanan yang lebih baik dibandingkan dengan varietas pembanding Gelora, Tit Super, Tombak, dan Trisula.

\section{UCAPAN TERIMA KASIH}

Terima kasih disampaikan kepada Badan Litbang Pertanian, Departemen Pertanian yang telah membiayai penelitian ini melalui Hibah Kerja Sama Kemitraan Penelitian Pertanian dengan Perguruan Tinggi (KKP3T) tahun 2011 dengan Nomor Kontrak 870/LB.620/I.1/3/2011, an. Dr. Muhamad Syukur.

\section{DAFTAR PUSTAKA}

BPS. 2011. Luas Panen, Produksi dan Produktivitas Cabai. http://www.bps.go.id. [30 September 2011].

Direktorat Jenderal Hortikultura. 2006. Pedoman Pelepasan Varietas Hortikultura. Departemen Pertanian. Jakarta. 128 hal.

Duriat, A.S. 1996. Cabai merah: komoditas prospektif dan andalan, hal. 1-3. Dalam A.S. Duriat. A. Widjaja, W. Hadisoeganda, T.A. Soetiarso, L. Prabaningrum $(E d s)$. Teknologi Produksi Cabai Merah. Balai Penelitian Tanaman Sayuran. Lembang.

Greenleaf, W. H. 1986. Pepper breeding. In M.J. Basset $(E d$.). Breeding Vegetables Crops. AVI Publishing Co. Conecticut.

Mastaufan, S. A. 2011. Uji Daya Hasil 13 Galur Cabai Merah IPB pada Tiga Lingkungan. Skripsi. Departemen Agronomi Hortikultura Fakultas Pertanian IPB. Bogor. 73 hal.

Semangun, H. 2000. Penyakit-penyakit Tanaman Hortikultura di Indonesia. Gadjah Mada University Press. Yogyakarta. 850 hal.

Suryaningsih, A., R. Sutarya, dan A. S. Duriat. 1996. Penyakit tanaman cabai merah dan pengendaliannya, hal 64-84. Dalam A. S. Duriat, A. W. W. Hadisoeganda, T. A. Soetiarso dan L. Prabaningrum (Eds.). Teknologi Produksi Cabai Merah. Balitsa. Lembang. 
Syukur, M., S. Sujiprihati, R. Yunianti, dan D.A. Kusumah. 2010. Evaluasi daya hasil cabai hibrida dan daya adaptasinya di empat lokasi dalam dua tahun. Jurnal Agronomi 38(1):4351 .
Widodo. 2007. Status of chili anthracnose in Indonesia, p.27.In D. G. OhandK.T.Kim(Eds.).Abstracts of The First International Symposium on Chili Anthracnose. Horticultural Technology Press. Seoul. 